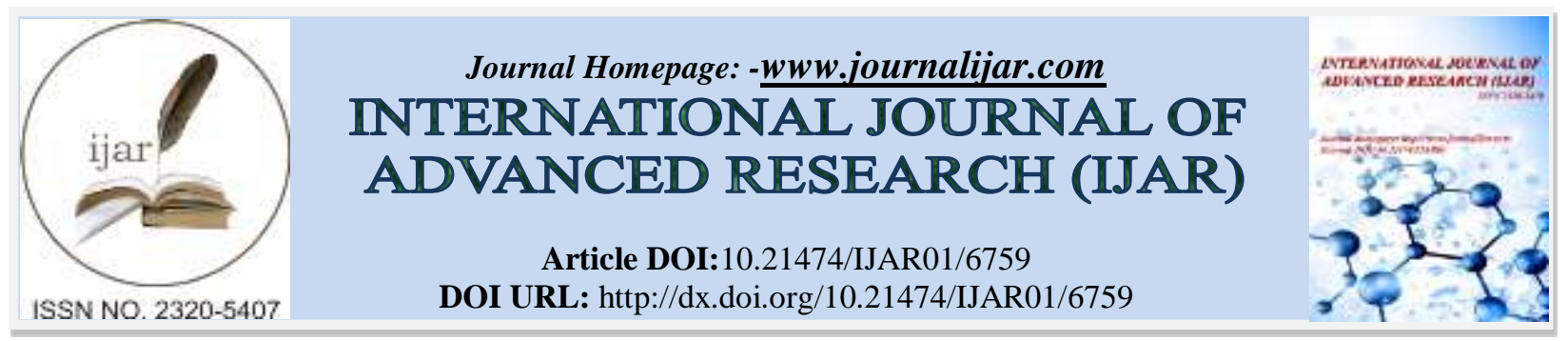

RESEARCH ARTICLE

\title{
EXPRESSION OF MUC2 IN NORMAL GASTRIC MUCOSA, INTESTINAL METAPLASIA AND GASTRIC CARCINOMA BY IMMUNOHISTOCHEMISTRY.
}

\section{Shuaeb Bhat ${ }^{1}$, R.P.Tania ${ }^{2}$, Irfan Ansari ${ }^{3}$, Shaffy Thukral ${ }^{4}$, Saleem Hussain ${ }^{1}$, Shareefa Akhter ${ }^{1}$, Fatima Rahim $^{5}$ and B.R.Sahaf ${ }^{6}$.}

1. Senior Resident, Department of Hematopathology, Sher-I-Kashmir Institute Of Medical Science, Soura, India.

2. Consultant Pathologist, Department of Pathology, Shusrusha Hospital, Mumbai, India.

3. Associate Professor, Department of Pathology, College of Medicine, Taibah University.

4. Assistant Professor, Department of Pathology, Adesh Medical College, Bathinda, India.

5. Technologist, Department of Hematopathology, Sher-I-Kashmir Institute Of Medical Science, Soura, India.

6. Lecturer, Department of Pathology, SKIMS Medical College, Bemina, J \&K, India.

\section{Manuscript Info}

Manuscript History

Received: 16 January 2018

Final Accepted: 18 February 2018

Published: March 2018

Keywords:-

MUC2, Immunohistochemistry, gastric cancer, intestinal metaplasia.

\section{Abstract}

Aim: Carcinomas of the stomach are a heterogeneous group of lesions in terms of architecture, pattern of growth, cell differentiation, and histogenesis. Altered MUC 2 expression patterns have been reported previously in intestinal metaplasia as well as in gastric cancer which include increased mucin heterogeneity, glycosylation changes and de novo expression of MUC2 in intestinal metaplasia as well as gastric carcinoma suggesting that MUC2 alterations can be regarded as "molecular" markers of malignant transformation of gastric mucosa. The aim of the study is to analyze the expression pattern of Mucin MUC2 in Normal, Pre-Neoplastic \& Neoplastic Gastric Epithelium. Materials and methods: Formalin fixed paraffin embedded sections of sixty cases which include twenty cases of each normal gastric mucosa, intestinal metaplasia and gastric carcinoma were taken up for the study and subjected to immunohistochemistry using MUC2.

Results : The intensity of MUC2 immunostaining in normal gastric mucosa, intestinal metaplasia and gastric carcinoma was evaluated . Immunoreactivity was graded as 0 (negative), \pm (trace positive), + (positive), or ++ (strongly positive). Statistical analysis was performed with Chi-Square test and significant differences were noted between these 3 groups. ( $\mathrm{p}$ value $<0.05$ ).

Conclusion: Mucin expression in intestinal metaplasia and gastric carcinoma is fairly complex. However, we conclude that MUC2 expression rates might be good parameters in progression of intestinal metaplasia to gastric carcinoma and might be a good prognostic marker for gastric carcinoma as it is very well implicated in understanding of gastric carcinogenesis. 


\section{Introduction:-}

Gastric mucins are critical cytoprotective proteins synthesized by gastric epithelial cells[1]. According to their structure and function, mucins can be divided into secreted mucins and transmembrane mucins. Secreted mucins can be gel-forming or non-gel-forming, and include MUC2, MUC5AC, MUC5B, MUC6, MUC7, MUC8, MUC9 and MUC19. Transmembrane mucins include MUC1, MUC3A, MUC3B, MUC4, MUC11, MUC12, MUC13, MUC15, MUC16, MUC17, MUC20 and MUC21 [2].

The genes for mucin MUC2 is found in a cluster on chromosome 11p15.5 and codes for a typical secretory mucin which is predominantly found in colorectal goblet cells. The normal gastric mucosa does not express MUC2 [3,4,5] . Altered mucin expression patterns have been reported previously in intestinal metaplasia as well as in gastric cancer which include increased mucin heterogeneity, glycosylation changes and de novo expression of MUC2 in gastric carcinoma $[6,7,8]$. These observations suggest that MUC2 alterations can be regarded as "molecular" markers of malignant transformation of gastric mucosa. Keeping all these alterations in mind, in this present study we have characterized the pattern of MUC2 expression in normal gastric mucosa, intestinal metaplasia and gastric carcinoma

\section{Materials and Methods:-}

The study was conducted at Meenakshi Medical College Hospital and Research Institute, Kanchipuram, Tamil Nadu. Sixty cases were selected , 20 cases each of normal gastric mucosa, intestinal metaplasia and gastric carcinoma. All cases were analyzed for their expression of mucin MUC 2( BIOGENEX USA) by IHC.

Gastrectomy specimens of 20 patients (15 males, 5 females) with gastric carcinomas diagnosed in the department of pathology in a tertiary care hospital were selected for this study. The data on the age, sex and other clinical details of the patients were obtained by reviewing clinical charts and pathological records. Hematoxylin-eosin slides of the cases were evaluated and findings were noted in the prescribed data sheet. This study was performed after written informed consent obtained from the patients. Histological classifications, according to the Lauren's macroscopic classification[9], according to the Borrmann's classification[10] and the World Health Organization (WHO) [11]were done.

Normal tissue and tissue with intestinal metaplasia were obtained from specimens immediately adjacent to carcinomas (transitional mucosa) or histologically normal mucosa obtained from the resection margins of the surgical specimen or endoscopic biopsies received in the department of pathology.

The use of histologically normal resection margins from patients undergoing gastric resection may not be the ideal normal control. Previous studies have compared the immunohisto-chemical staining using mucin antibodies in normal surgical resection margins of cancer specimens to the staining observed in normal biopsy specimens from patients with normal stomach determined by endoscopy. They found that the quality of staining for all antibodies was no different in these two groups, with the exception that the intensity of staining was slightly less in the endoscopic biopsies compared with the surgical resection margins. These data support the use of resection margins as normal tissue.

\section{Scoring system:-}

MUC2 expression is concentrated in perinuclear zone.

While the intensity of the staining was assessed as follows:

1. 0 (negative),

2. \pm (trace positive)

3. + (positive): $5-50 \%$ of cells were stained

4. ++ (strongly positive) $>50 \%$ of cells were stained

The immunostaining result was considered positive if at least $5 \%$ of the cells were stained. When less than $5 \%$ of neoplastic cells were stained, the immunostaining result was considered negative.

Statistical analyses:-

Statistical analyses of all results were done by using Chi square test at level of significance $\mathrm{p} \leq 0.05$ was done. 


\section{Ethical concern:-}

Ethical clearance was obtained from the Ethical committee meeting conducted at Meenakshi Medical College and Research Institute, Kanchipuram, Tamil Nadu, India.

\section{Results:-}

The present study is a descriptive (retrospective + prospective) study done from January 2010 to June 2012 in Meenakshi Medical College and Research Institute, Kanchipuram. Tamil Nadu.

In the present study age of the cases ranged from 23 to 78 years with mean age being 51.6 years. Majority of the intestinal metaplasia and gastric carcinoma cases were seen between 40 to 70 years of age. Mean age for intestinal metaplasia and gastric carcinoma was 44.3 years and 58.9 years respectively.

\section{Distribution of Intestinal Metaplasia:-}

In the present study total 20 cases of intestinal metaplasia were taken. Among these 20 cases $13(65 \%)$ cases were seen along with gastric adenocarcinoma while 7 (35\%) cases were either associated with chronic gastrit is or peptic ulcer. Out of these 20 cases of intestinal metaplasia 18 cases were taken either from subtotal or partial gastrectomy specimens and 2 cases were taken from endoscopic biopsies (Table:1). In this present study we further sub-divided intestinal metaplasia into complete type (type I) and incomplete type (type II). Ten cases of complete type and 10 cases of incomplete type of intestinal metaplasia were noted.

Table 1:- Distribution of intestinal metaplasia with gastric lesions

\begin{tabular}{|c|c|c|}
\hline Gastric Lesions & No. of Cases & Percentage \\
\hline Benign & 7 & 35 \\
\hline Malignant & 13 & 65 \\
\hline
\end{tabular}

\section{Distribution of Intestinal Metaplasia with Gastric Carcinoma:-}

Intestinal metaplasia was seen in association with 13 cases of gastric carcinoma. We further sub divided these 13 cases of gastric carcinoma according to type of intestinal metaplasia into complete or incomplete type. We observed $8(62 \%)$ cases of complete type and $5(38 \%)$ cases of incomplete type intestinal metaplasia associated with gastric carcinoma cases.

\section{Classification Of Gastric Carcinoma:-}

In present study Gastric carcinomas were classified according to Lauren's, Borrmann's and WHO classifications. According to Lauren's classification [9] 15(75\%) cases were of intestinal type and 5(25\%) cases were of diffuse type in this study. In this study according to Borrmann's classification[10], $2(10 \%)$ cases were of polypoid type (type 1), 3 (15\%) cases were of fungiform type (type 2), $10(50 \%)$ cases were of ulcerated type (type 3 ) and 5 (25\%) cases were of diffuse type (type 4). In this study, according to WHO classification[11] 10 (50\%) cases of tubular/papillary type, $6(30 \%)$ cases of signet ring type and $2(10 \%)$ cases of each mucinous and undifferentiated type were noted.

\section{Expression Pattern of MUC 2:-}

MUC2 was not detected in normal gastric mucosa(Fig 1a \&1b).

\section{Expression Pattern of MUC 2 in Complete Intestinal Metaplasia:-}

Among the 7 cases of complete intestinal metaplasia, MUC2 was expressed strongly and 2 cases showed moderate immunoreactivity and weak staining was seen in 1 cases(Fig $2 a \& 2 b)$.

\section{Expression Pattern of MUC2 in Incomplete Intestinal Metaplasia:-}

MUC2 was strongly expressed in 5 cases of incomplete intestina. While 2 cases showed moderate and 3 cases showed weak positivity.

\section{Expression Pattern of MUC2 in Gastric Carcinoma:-}

MUC2 expression was seen in 18 cases(Fig 3a\&3b). Nine cases showed strong MUC2 immunoreactivity while 5 cases showed moderate, 4 cases were weakly reactive for MUC2. While negative immune reactivity for MUC2 was observed in 2 cases. Expression of MUC2 are summarized in table 2. 
Table 2:-Expression of MUC2 in Normal, Intestinal metaplasia and Gastric Carcinoma

\begin{tabular}{|c|c|c|c|c|}
\hline \multirow{2}{*}{ Histopathology Diagnosis } & \multicolumn{4}{|c|}{ MUC 2 } \\
\cline { 2 - 5 } & ++ & + & $\mathbf{\pm}$ & - \\
\hline Normal & 0 & 0 & 0 & 20 \\
\hline Intestinal metaplasia & 12 & 4 & 4 & 0 \\
\hline Gastric Carcinoma & 9 & 5 & 4 & 2 \\
\hline
\end{tabular}

Fig 1a:-Normal histology of gastric mucosa.

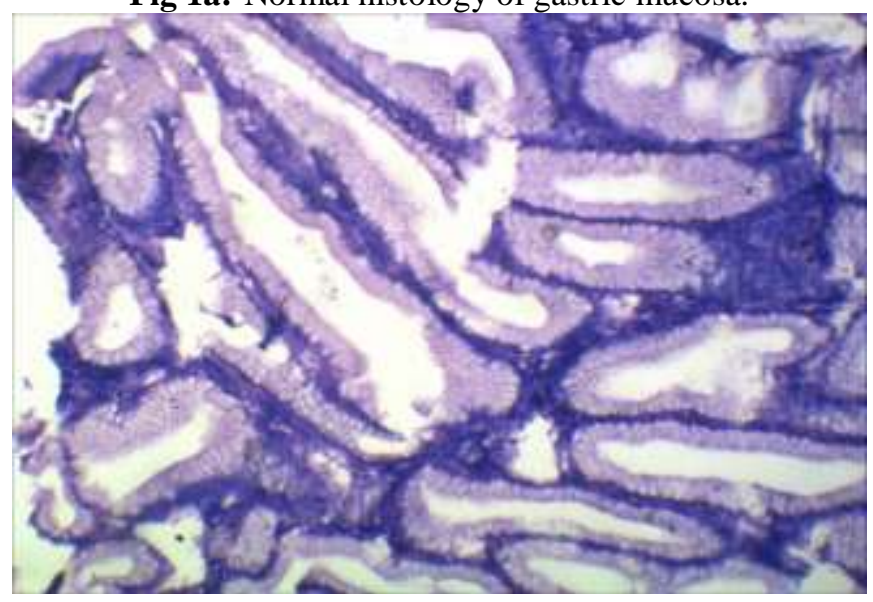

Fig 1b:- MUC2 IHC of normal gastric mucosa

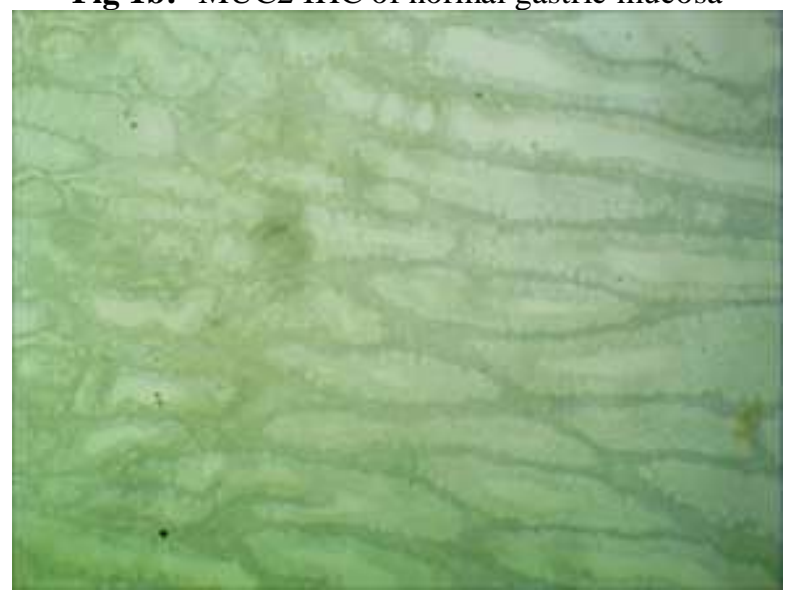

Fig 2a:- Intestinal metaplasia of gastric mucosa.

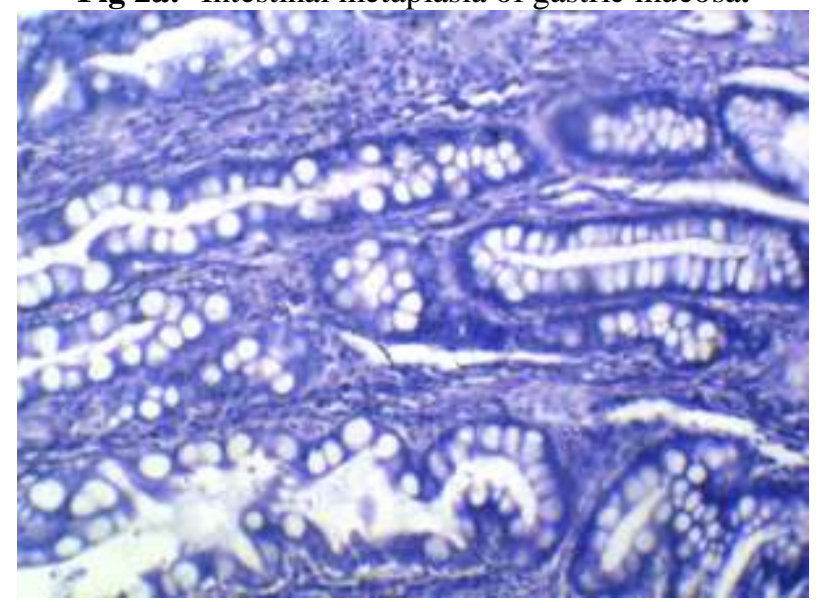


Fig 2b:- Muc 2a IHC in case of intestinal metaplasia

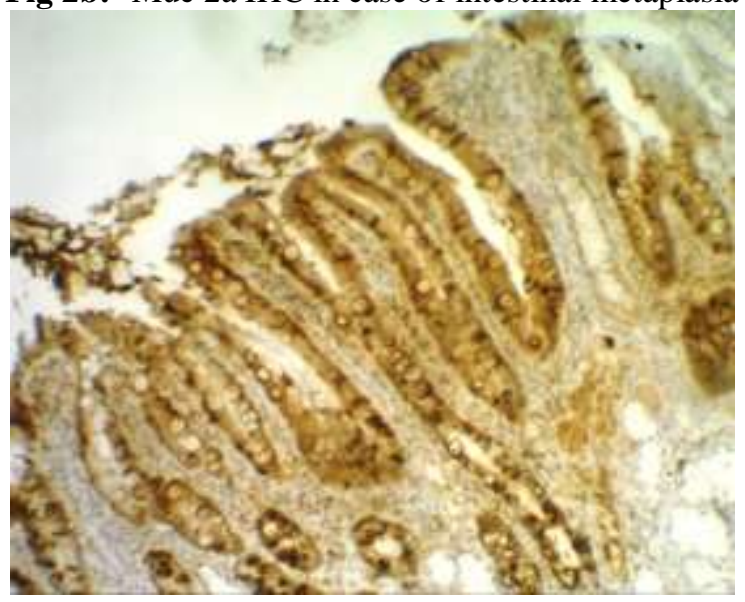

Fig 3a:- histology of gastric carcinoma

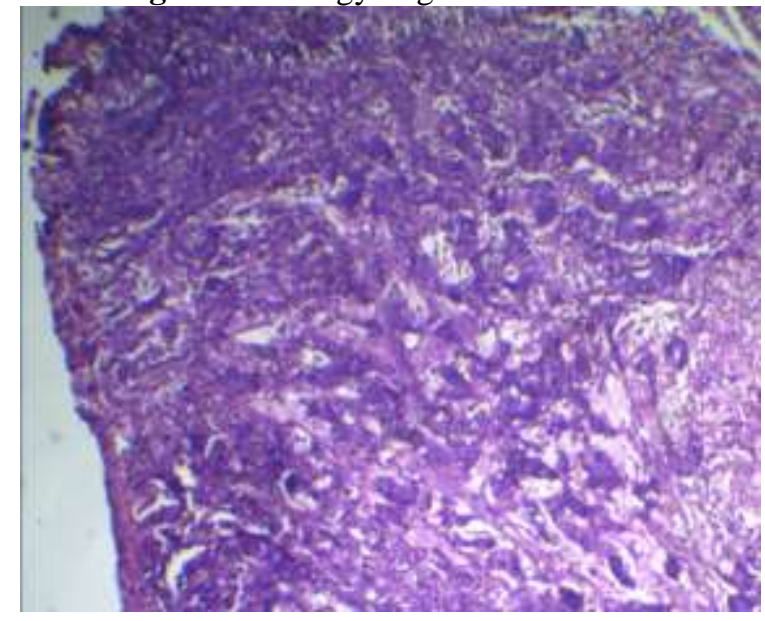

Fig 3b:- MUC 2 IHC of gastric carcinoma.

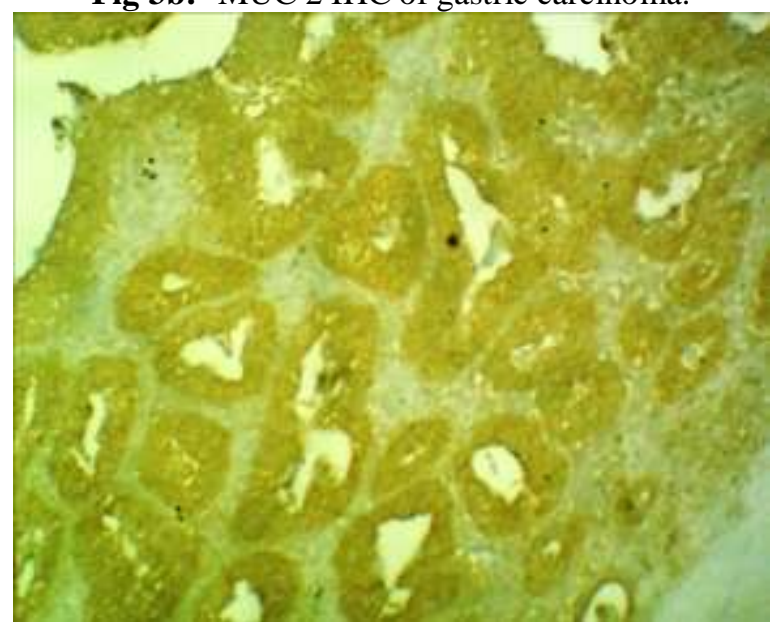

\section{Discussion:-}

In the present study total 60 cases were studied comprising 20 cases of each normal gastric mucosa, intestinal metaplasia and gastric carcinoma.In our study the age of the cases ranged from 23 to 78 years with mean age being 54.6 years. Majority of the intestinal metaplasia and gastric carcinoma cases were seen between 40 to 70 years of age. In present study for our convenience we have broadly divided intestinal metaplasia in two types (A) Complete 
type and (B) Incomplete type. We observed 10 cases of complete type and 10 cases of incomplete type. Reis CA, David L et al[5] in their study noted 20 cases of complete type and 26 cases of incomplete type intestinal metaplasia.In present study intestinal metaplasia was noted with both benign and malignant cases. Seven $(35 \%)$ cases were seen with benign conditions like chronic gastritis or peptic ulcers while $13(65 \%)$ cases were observed along with gastric carcinoma. The comparison of intestinal metaplasia in our study and other studies is given in table 3 .

Table 3:- Comparison of intestinal metaplasia with benign and malignant gastric lesions

\begin{tabular}{|c|l|c|c|}
\hline S. No & \multicolumn{1}{|c|}{ Study } & Benign (\%) & Gastric Carcinoma (\%) \\
\hline 1 & Jass, J. R. \& Filipe, M. I (1981)[12] & 42.85 & 93 \\
\hline 2 & Segura DI \& Montero C (1983)[13] & 80.7 & 96 \\
\hline 3 & Silva, S. \& Filipe, M. I (1986)[14] & 24.5 & 65 \\
\hline 4 & You WC \& Blot WJ (1993) [15] & 39.8 & 66.6 \\
\hline 5 & Present Study & 35 & 65 \\
\hline
\end{tabular}

Classification of Gastric Carcinoma:-

We classified gastric carcinomas according to Lauren's, Borrmann's and WHO classification and following tables (Table:4, Table:5\&Table:6) compare our results with the results of other studies.

Table 4:- Comparison of gastric carcinoma cases according to Lauren's classification

\begin{tabular}{|c|c|c|c|c|c|c|c|c|}
\hline \multirow{2}{*}{$\begin{array}{c}\text { Lauren's } \\
\text { Classification }\end{array}$} & \multicolumn{2}{|c|}{$\begin{array}{c}\text { Celso A. Reis[16] } \\
\text { (2000) }\end{array}$} & \multicolumn{2}{c|}{$\begin{array}{c}\text { Roessler K et al[17] } \\
\text { (2005) }\end{array}$} & $\begin{array}{c}\text { Ozgur Ilhan et al[18] } \\
\text { (2010) }\end{array}$ & \multicolumn{2}{c|}{$\begin{array}{c}\text { Present study } \\
\text { (2012) }\end{array}$} \\
\cline { 2 - 9 } & No & \% & No & \% & No & \% & No & \% \\
\hline Intestinal & 52 & 63.4 & 85 & 44.8 & 217 & 84.4 & 15 & 75 \\
\hline Diffuse & 30 & 36.6 & 105 & 55.2 & 40 & 17.6 & 5 & 25 \\
\hline
\end{tabular}

Table 5:- Comparison of gastric carcinoma cases according to Borrmann's classification

\begin{tabular}{|c|c|c|c|c|c|c|c|c|}
\hline Borrmann's Classification & \multicolumn{2}{|c|}{$\begin{array}{c}\text { Ming S.C[19] } \\
\text { (1977) }\end{array}$} & \multicolumn{2}{|c|}{$\begin{array}{c}\text { Roessler K et } \\
\text { al[17] } \\
\text { (2005) }\end{array}$} & $\begin{array}{c}\text { Ozgur Ilhan et } \\
\text { al[18] (2010) }\end{array}$ & \multicolumn{2}{|c|}{$\begin{array}{c}\text { Present study } \\
\text { (2012) }\end{array}$} \\
\cline { 2 - 9 } & No & $\%$ & No & \% & No & \% & No & \% \\
\hline Polypoid (Type 1) & 43 & 25 & 54 & 28.4 & 8 & 3.1 & 2 & 10 \\
\hline Fungiform (Type 2) & 10 & 6 & 22 & 11.6 & 5 & 1.9 & 3 & 15 \\
\hline Ulcerated (Type 3) & 73 & 43 & 20 & 10.5 & 218 & 84.8 & 10 & 50 \\
\hline Diffuse (Type 4) & 45 & 26 & 94 & 49.5 & 26 & 10.2 & 5 & 25 \\
\hline
\end{tabular}

Table 6:- Comparison of gastric carcinoma cases according to WHO classification

\begin{tabular}{|c|c|c|c|c|c|c|}
\hline \multirow{2}{*}{ WHO Classification } & \multicolumn{2}{c|}{$\begin{array}{c}\text { Roessler K et al[17] } \\
\text { (2005) }\end{array}$} & \multicolumn{2}{c|}{$\begin{array}{c}\text { Ozgur Ilhan et al[18] } \\
\text { (2010) }\end{array}$} & \multicolumn{2}{c|}{ Present study (2012) } \\
\cline { 2 - 7 } & No & \% & No & \% & No & \% \\
\hline Tubular/Papillary & 80 & 42.1 & 164 & 63.8 & 10 & 50 \\
\hline Mucinous & 4 & 2.1 & 21 & 8.2 & 2 & 20 \\
\hline Signet Ring & 85 & 44.7 & 19 & 7.3 & 6 & 30 \\
\hline Undifferentiated & 21 & 11 & 53 & 20.6 & 2 & 20 \\
\hline
\end{tabular}

\section{Mucin Expression:-}

MUC2 was not detected in normal gastric mucosa. The overall profile of mucin expression in type I (complete) and type II(incomplete) intestinal metaplasia is characterized by de novo expression of the MUC2. The overall profile of mucin expression in gastrc carcinoma is characterized by de novo expression of the MUC2. Table 7 compares the expression of MUC2 in our study with other studies. 
Table 7:- Comparison of overall profile of MUC 2 in normal gastric mucosa, intestinal metaplasia and gastric carcinoma

\begin{tabular}{|c|c|c|c|c|c|c|}
\hline \multirow[t]{2}{*}{ S. No } & \multirow[t]{2}{*}{ Study } & \multirow[t]{2}{*}{ No. of Cases } & \multicolumn{4}{|c|}{ MUC 2 percentage } \\
\hline & & & $\mathbf{0}$ & 1 & 2 & 3 \\
\hline 1 & $\begin{array}{l}\text { Hong-Kai Zhang et al[20] } \\
\text { (2004) }\end{array}$ & $\mathrm{Ca}(33)$ & 6 & 8.4 & 21.2 & 63.6 \\
\hline \multirow[t]{3}{*}{2} & \multirow{3}{*}{$\begin{array}{l}\text { Subramani DB. Et } \\
\text { al[21](2006) }\end{array}$} & $\mathrm{N}(7)$ & 100 & 0 & 0 & 0 \\
\hline & & $\operatorname{IM}(21)$ & 0 & 0 & 42.9 & 57.1 \\
\hline & & $\mathrm{Ca}(36)$ & 0 & 32.1 & 29 & 38.9 \\
\hline \multirow[t]{3}{*}{3} & \multirow[t]{3}{*}{ Ozgur Ilhan et al[18] (2010) } & $\mathrm{N}$ (nil) & - & - & - & - \\
\hline & & IM (186) & 0 & 22.6 & 19 & 58.4 \\
\hline & & $\mathrm{Ca}(257)$ & 9.3 & 15.1 & 24.2 & 51.4 \\
\hline \multirow[t]{3}{*}{4} & \multirow[t]{3}{*}{ Present Study (2012) } & $\mathrm{N}(20)$ & 100 & 0 & 0 & 0 \\
\hline & & $\operatorname{IM}(20)$ & 0 & 20 & 20 & 60 \\
\hline & & $\mathrm{Ca}(20)$ & 10 & 20 & 25 & 45 \\
\hline
\end{tabular}

In agreement with previous studies reporting the distribution of mucins in normal stomach, we found expression of MUC2 was usually not detected in normal gastric mucosa as described in the previous reports Ho SB et al,[7] and Reis $\mathrm{Ca}$ et al,[8]

Intestinal metaplasia is one of the lesions identified in the cascade of event that precedes the development of gastric carcinoma. Intestinal metaplasia is accompanied by the induction of de-novo expression MUC2 as well as in gastric cancer.

\section{Conclusion:-}

Taking together our data on mucin expression (MUC 2) in normal gastric mucosa, intestinal metaplasia and gastric cancer, we observed that intestinal metaplasia is accompanied by the induction of de novo expression MUC2. These alterations may favour the development of gastric carcinoma. The present study suggests that MUC2 is a marker of intestinal metaplasia and may be used for the early detection of this lesion in pre-neoplastic human gastric epithelium.

The present study observed de novo expression of MUC 2 in gastric cancer. Recently, various studies have shown that the methylation in the promoter region of the MUC2 gene is determinant for the expression of MUC2 in colon carcinoma cell lines. This mechanism of control of MUC2 gene expression in gastric carcinomas should be addressed in future studies.

Mucin expression in intestinal metaplasia and gastric carcinoma is fairly complex. However, we conclude that MUC 2 expression rates might be good parameters in progression of intestinal metaplasia to gastric carcinoma and might be a good prognostic marker for gastric carcinoma as it is very well implicated in understanding of gastric carcinogenesis. 


\section{Bibliography:-}

1. Kim Y. S., Gum J., Jr., Brockhausen I. Mucin glycoproteins in neoplasia.Glycoconj. J., 13: 693-707, 1996.

2. Andrianifahanana M, Moniaux N, Batra SK. Regulation of mucin expression: mechanistic aspects and implications for cancer and inflammatory diseases.Biochim Biophys Act,; 1765: 189-222, 2006.

3. Kanoh A, Takeuchi H, Kato K, Waki M, Usami K, Irimura T. Interleukin-4 induces specific pp-GalNAc-T expression and alterations in mucin Oglycosylation in colonic epithelial cells. Biochim Biophys Acta,1780: 577-584, 2008.

4. Byrd JC, Bresalier RS. Mucins and mucin binding proteins in colorectal cancer. Cancer Metastasis Rev,23: 7799, 2004.

5. Celso A. Reis, Leonor David, Pelayo Correa. Et al. Intestinal Metaplasia of Human Stomach Displays Distinct Patterns of Mucin (MUC1, MUC2,MUC5AC, and MUC6) Expression. Cancer Res. March 1, 59; $1003,1999.98$

6. Correa, P. A human model of gastric carcinogenesis. Cancer Res., 48: 3554-3560, 1988.

7. Ho S. B., Shekels L. L., Toribara N. W. et al. Mucin gene expression in normal, pre-neoplastic, and neoplastic human gastric epithelium. Cancer Res., 55: 2681-2690, 1995.

8. Reis C. A., David L., Nielsen P. A. et al. Immunohistochemical study of MUC5AC expression in human gastric carcinomas using a novel monoclonal antibody. Int. J. Cancer, 74: 112-121.

9. Lauren P. The two histological main types of gastric carcinoma:diffuse and so-called intestinal type carcinoma. ActaPathol Microbiol Scand 1965; 64: 31-49.

10. Borrmann R. Geschwulste des Magens und Duodenums.In: Henske F, Lubasch O, eds. Handbuch der SpeziellenPathologischen Antomie und Histologie. Berlin: JuliusSpringer, 1926.

11. Hamilton S, Aaltonen LA. Tumours of the stomach in World Health Organization Classification of Tumours of the Digestive System. Lyon: IARCH Press, 2000; Chapter 3; 37-66.

12. Jass, J. R., and Filipe, M. I. The mucin profiles of normal gastric mucosa,intestinal metaplasia and its variants and gastric carcinoma. Histochem. J.,73:931-939, 1981

13. Segura DI, Montero C. Histochemical characterization of different types of intestinal metaplasia in gastric mucosa. Cancer. 1983;52:498-503.

14. Silva, S., and Filipe, M. I. Intestinal metaplasia and its variants in the gastric mucosa of Portuguese subjects: a comparative analysis of biopsy and gastrectomy material. Hum. Pathol., 17: 988-995, 1986.

15. You WC, Blot WJ, Li JY, Chang YS, Jin ML, Kneller R, Zhang L, et al. (1993) Precancerous gastric lesions in a population at high risk of stomach cancer. Cancer Res 53:1317-1321

16. Celso A. Reis, Leonor David, Filipa Carvalho, Ulla Mandel et al. Immunohistochemical Study of the Expression of MUC6 Mucin and Coexpression of Other Secreted Mucins (MUC5AC and MUC2) in Human Gastric Carcinomas. J Histochem Cytochem 2000 48: 377

17. Kristina Roessler, Stefan P. Mönig, Paul M. Schneider, Franz-Georg Hanisch et al. Co-expression of CDX2 and MUC2 in gastric carcinomas: Correlations with clinico-pathological parameters and prognosis World $\mathbf{J}$ Gastroenterol 2005;11(21):3182-3188.

18. Ozgur ILHAN, Unsal HAN, Binnur ONAL, Serkan Yasar CELIK. Prognostic significance of MUC1, MUC2 and MUC5AC expressions in gastric carcinoma. Turk J Gastroenterol 2010; 21 (4): 345-352.

19. Si-Chung Ming. Gastric Carcinoma: A Pathological Classification. Cancer 1977; 39: 2475 - 2485

20. Hong-Kai Zhang, Qiu-Min Zhang, Tie-Hua Zhao, Yuan-Yuan Li, Yong-Fen Yi. Expression of mucins and Ecadherin in gastric carcinoma and their clinical significance. J Gastroenterol 2004 October 15;10(20):30443047.

21. Subramani Durai Babu, Venkataraman Jayanthi, Niranjali Devaraj, Celso A Reis, Halagowder Devaraj. Expression profile of mucins (MUC2, MUC5AC and MUC6) in Helicobacter pylori infected pre-neoplastic and neoplastic human gastric epithelium. Molecular Cancer 2006, 5:10. 1-7. 